\title{
The Research on Knowledge Ontology Construction of Information Technology Course in Middle School Based on Semantic WEB
}

\author{
Jun Yuan \\ The School of computer \& information, Qiannan Normal College for Nationalities, Duyun, Guizhou, \\ China, 55800
}

Keywords: Research on ontology construction; Information technology curriculum in middle school; Based on semantic WEB

\begin{abstract}
Semantic Web is the development direction of web technology nowadays; ontology is an important part of Semantic Web. The ontology of curriculum knowledge is a clear and standardized description of the relationship between concepts in a certain course, and the knowledge system which is built on the basis of common recognition. At present, there are many problems in the course of network Learning resources construction and use. This paper takes the curriculum Knowledge ontology construction of Information Technology Foundation in senior high school as an example, firstly, this paper introduces the unified standard of network Learning resources construction, then introduces ontology, according to the teaching order of course knowledge, follows the teaching law of course, and realizes the knowledge ontology of information technology base course with the method of ontology construction widely used at present. It lays a foundation for the research of personalized learning, intelligent answer and semantic retrieval of the related course network resources by using Semantic Web technology.
\end{abstract}

\section{Introduction}

Semantic Web is the web that computers can understand information semantics; it is the development direction of web technology nowadays. Ontology is an important part of Semantic Web, which can define the concept of domain clearly, and describe the relationship between concepts, thus connecting many concepts in the field into a complex, machine-understandable concept network; [1]Ontology is the basis of semantic search, sharing and reuse of knowledge in the network. In recent years, with the popularization and application of network Learning mode, a large number of curriculum network resources have been established, which provides a variety of learning resources for related courses, and also makes it possible for students to develop their own learning ability. However, after many years of development, there are still a lot of problems in curriculum Network Learning resources in the construction and the use of the process as follows: firstly, the existing Curriculum network resource sharing difficulties, there is duplication of construction, information Island phenomenon. Secondly, the curriculum network Learning resources in the construction process did not follow the unified technical standards, knowledge points of the hierarchical structure and logical relationship are not clear, no considering the semantic relations between resources. So, it is difficult to achieve different systems, different applications of network education resources utilization and sharing. Confronting the existing problems in the construction of network education resources, this article takes course network resources construction information Technology the middle school as an example. Firstly, this paper introduces the unified standard for the construction of network Learning Resources--Technical specification of educational resources Construction in China (CELTS); Then, in order to solve the problem of the logical relationship of the hierarchical structure of network resources in the course of information technology in middle school, it introduces the ontology, we try to describe the construction process of curriculum Knowledge ontology, the ontology of Information Technology Foundation is realized by the method of ontology construction, in order to overcome the existing problems of network resources, to improve the utilization efficiency of network education resources, and to realize the individualized learning and intelligent answer of the related course network resources by using the Semantic Web technology, semantic retrieval and other research have laid a 
foundation.

\section{The Network Education Resources Construction Norms and Metadata}

In order to avoid information island, to realize the efficient retrieval, use and give the evaluation of network education resources, the course network learning resource construction must follow the unified technical standard, CELTS is the abbreviation of China Network Education Technology Standard system, it is the Technology Standards proposed by Learning Technology Standardization Committee in Learning Object Metadata Specification (low).the following is the introduction about the CELTS and metadata .

The Standard of Network Education Resources Construction. CELTS is the abbreviation of China Network Education Technology Standard system (Chinese E-Learning Technology standards), It is the education related application software realizes the network education resources sharing, the information exchange and the system interoperability ability Unified technical standard. CELTS by the "National Information Technology Standardization Technical Committee (CELTSC)" authorized to undertake the national education information technology related standards of development, certification and application promotion work [2].China's network Education Technology Standard System (CELTS) includes five items: guidance, learning environment, learning resources, learners, education Management.

China's network education technology standard system and network curriculum resources construction related mainly contain the education resources construction Norm (CELTS-41)", it mainly provides the normative standard for the network education resources design, the development, the search and the management process. CELTS-41 is based on the Learning Object Metadata specification (low) in order to ensure the quality, use value of the network education resources, extend the resource evaluation, the structure and function of the resource database to meet the reality of the construction of educational resources in China. CELTS-41 has standardized the technical behavior of the developer, realized the consistency of the resource attribute structure, and provided the powerful support for the realization of the efficient retrieval, use, evaluation and sharing of the network education resources.

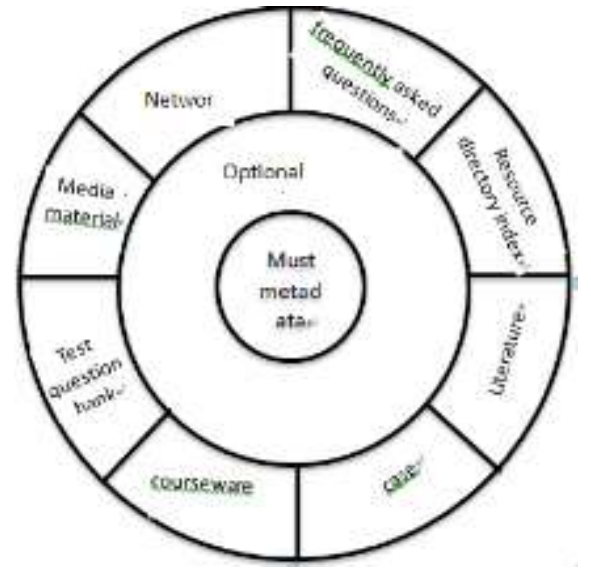

Figure 1. Finite The Basic structure Chart of educational resources construction (CELTS-41)

As shown above, the basic structure of educational resources construction criterion (CELTS-41) is composed of three parts: classification element, optional universal data element and necessary data element. Classification elements are formed by Test database, Course courseware, course knowledge case, course literature material, media material material, network course, FAQ, Resource Catalogue Index composition. According to the characteristics of different educational resources, the extended attribute of specific resources, such as audio and video resources channel number, quantization digit and so on are included in Classification elements; Optional Common data Elements from the Learning Object Metadata Specification (Low) in the specification of all kinds of educational resources are suitable for the collection of attributes, which can be selected to use in the construction of resources, such as network resources download times, clicks and so on; 
The required data elements are based on the main categories in the metadata structure in the Learning Object Metadata specification (low). All types of education resources must have and follow the elements, they have the greatest versatility, as the basis for resource interoperability, such as: title, subject, format, size and so on.

Meta Data Overview. Metadata (metadata) is also referred to as mediation data, which is derived from the Greek language, which means "in ... After "[3], the metadata also referred to the data of data, used to provide information on the attributes of data, to facilitate the implementation of indicators to indicate the location of data storage, data retrieval and search, access and use, metadata is the definition and description of other data of data. In the construction of network education resources, metadata is used to describe the attribute information of the network education resources so as to be used in the related application. The specific functions of metadata in describing network education resources are as follows:

Resource Description, describing the location and resource content of the network education resources so as to realize the access, utilization and retrieval of resources.

Resource retrieval, Metadata is similar to electronic directories including the basic information of resource search, which describes the content and characteristics of resource data, and facilitates the rapid and accurate retrieval of resources.

Resource Evaluation, Metadata provides attribute information of resources, which contains the basic content of format, name, size, etc., through which the user does not have to open resources to the type, function, etc.

Resource Selection, Metadata provides resource descriptions that include the location, content, format, and name of the resource, and the description of the content, which helps users assess resources to make decisions about resource choices. The following is an example of the Web-education resource metadata instance, "How do I work with SWF", to help understand the concept of metadata:

Table 1 Metadata example of network teaching resources: Web Working principle

\begin{tabular}{|c|c|c|}
\hline \multicolumn{3}{|c|}{ Metadata example of network teaching resources: Web Working principle } \\
\hline Must data element & $\begin{array}{c}\text { optional data } \\
\text { element }\end{array}$ & $\begin{array}{l}\text { category element } \\
\text { (extension set) }\end{array}$ \\
\hline ID: 000369 & Audit: By & playback time: 52 \\
\hline Title: How the Web works & downlo: & nlavback Sneed. \\
\hline & of times: 101 & 20 Frames/sec \\
\hline Introduction: Users enter a & Applicable object: & \\
\hline $\begin{array}{l}\text { different URL, you can open a } \\
\text { specific Web server's corresponding }\end{array}$ & Senior Grade & \\
\hline documents, download to the & & \\
\hline browser, the browser explains the & & \\
\hline animation, sound, text and graphics & & \\
\hline images, as well as the need for & & \\
\hline $\begin{array}{l}\text { further links to the URL, to show } \\
\text { the user is rich hypertext }\end{array}$ & & \\
\hline information. & & \\
\hline $\begin{array}{l}\text { Keywords: Web work principle } \\
\text { Resource upload: Liu }\end{array}$ & & \\
\hline Knowledge Point: Web resource & & \\
\hline $\begin{array}{l}\text { upload time: } 2017-7-9 \text { format: } \\
\text { SWF size } 80 \mathrm{~KB}\end{array}$ & & \\
\hline $\begin{array}{l}\text { SWF size: 80KB } \\
\text { Resource Location: }\end{array}$ & & \\
\hline Icomputerlresourcelvideol00369.sw & & \\
\hline
\end{tabular}

\section{Overview of Curriculum Knowledge ontology and construction method}

Ontology. Ontology first appeared in the 17th century, the original is a philosophy of the concept of the essence of the existence of objective things and the composition of the real existence in any field to make an objective description. [4]Since this century, with the rapid development of 
information technology, which is represented by computer and network, ontology has gone beyond philosophy, and has been widely used in knowledge engineering and information technology, which has promoted the development of technology fields such as Natural language processing and intelligent software Research. In the field of information science, the definition of the term "ontology" is different from that of scholars. Ontology is an accurate description of conceptualization and it is used to describe the nature of things. The professor Gruber at Stanford University in the United States in 1995 claimed "The domain ontology is the concept system, clear, formalized specification description the role of domain ontology and the building". Gruber's definition of ontology has been recognized by most people, which is accepted by most people in a certain field. [5] Ontology can define domain concepts clearly and describe the relationship between concepts, thus connecting many concepts in the field into a complex, machine-understandable concept network, which makes ontology play an important role in knowledge representation and semantic analysis. It has a wide application foreground in intelligent retrieval, information processing, intelligent answering, and individualized learning and so on in the heterogeneous system.

Curriculum Knowledge Ontology. Curriculum Knowledge ontology is a clear and standardized description of the relationship between concepts in a certain course, and a commonly recognized knowledge system based on it. [6]Taking the course of Information Technology Foundation in first grade of Senior High School as an example, conforming to the teaching order of course knowledge, following the course teaching law, the key concepts in the course are screened, the relationship between concepts is clearly described, and the knowledge ontology of the course of Information Technology Foundation is constructed. The curriculum Knowledge Ontology of Information Technology Foundation mainly consists of curriculum core concept, concept relationship and formal description language of machine recognition of WOL(Web Ontology Language), which is a knowledge system that can be understood and recognized by computer in this course.

By labeling the relevant network education resources in the course of Information Technology Foundation, the paper can realize the classification, browsing and retrieval based on semantics of the related network education resources, which is the foundation of the development of the related network personalized learning software and intelligent learning and retrieval software.

Methods and Tools of Ontology Construction of Curriculum Knowledge. The main methods of constructing curriculum knowledge ontology are IDEF-5 method, skeleton method, Enterprise modeling method, seven steps of Stanford University Medical School, recycling method, etc. [7] The construction knowledge ontology in Information Technology Foundation Course mainly adopts "seven steps" and combines the logic structure of curriculum knowledge, according to the principle of abstraction to concrete. "Seven Steps" by Stanford University Medical School Noy and McGuinness proposed that it is the mainstream of domain ontology construction, seven-step in the process of ontology fully considering the existing ontology reuse, can simplify the construction process of ontology, seven steps by the following seven-step composition:

(1) Ontology demand analysis.

(2) Consider the reuse of existing ontology.

(3) List the core concepts and terminology in the domain ontology.

(4) Definition of core class (concept) and class hierarchy system

(5) Describing the attributes that define the concept.

(6) Defining the property's faceted (range of values).

(7) Creating an Ontology instance.

The construction tool of knowledge ontology in the course of Information Technology Foundation uses the protégé 4.1 software developed by Stanford University Medical School; protégé is an open source ontology editing software, which can improve the efficiency of ontology construction and maintenance. 


\section{The Curriculum Knowledge ontology Construction in Information Technology Foundation}

The Requirement Analysis of Knowledge Ontology in Information Technology Foundation Course. Before the construction of curriculum knowledge ontology, it is necessary to make clear the purpose, domain scope and user of the ontology. The construction of Knowledge ontology in the course of Information Technology Foundation is to describe the curriculum knowledge systematically, to organize and manage, clear the knowledge points of the curriculum and their relationship, to guide the learners to construct the relevant knowledge system of the curriculum correctly; The knowledge ontology of Information Technology Foundation is regarded as the curriculum Knowledge Foundation that peers and experts agree on. It can be used to annotate the network teaching resources and realize the application and sharing of the semantic level of the network curriculum resources. The scope of knowledge ontology in this course is the course field of Information Technology Foundation, and the users of the knowledge ontology of the Information Technology Foundation Course are: Curriculum teacher, learner and related application research, development personnel. The curriculum Knowledge Ontology of Information Technology Foundation uses OWL as the formal description language, which is helpful to realize the reuse and sharing of ontology.

Reuse of Existing Ontology. Curriculum knowledge is the knowledge system of curriculum sharing, sharing and reusing is the important goal of constructing curriculum knowledge ontology. Therefore, the reuse of existing knowledge ontology can simplify the process of ontology construction before ontology is constructed. However, as far as the knowledge ontology of Information Technology Foundation is concerned, there is no corresponding ontology for reuse extension, so we can refer to the Knowledge ontology of similar courses so as to realize the construction of knowledge ontology of the course of Information Technology Foundation. The curriculum Knowledge Ontology construction of Information Technology Foundation is followed by high School first grade(The Human Education Edition) .The Information Technology Foundation the textbook mainly, at the same time reference to the The Computer Information Technology Foundation as well as from the network related curriculum lesson plan, the courseware and so on.

Determine the Core Concept Set and Hierarchical Structure of Knowledge Ontology of Information Technology Basics. The construction of Knowledge ontology in the course of Information Technology Foundation of is based on the "Information Technology Foundation" teaching material in the first year of the human education edition. According to the course Knowledge teaching law and the teaching step, from top to bottom, the top root node is determined, the core concept of the course is determined, then the course knowledge is traversed through the core concept, which sets up the whole concept of curriculum according to the relation of knowledge. In the establishment of curriculum concept set, we should also pay attention to the "knowledge granularity" problem; knowledge granularity is the particle size of knowledge representation, that is, the determination of meta- knowledge points, the so-called meta knowledge points, that is, "no more points" knowledge points. Theoretically speaking, division knowledge of the smaller particle size, the more conducive to the reuse of knowledge, and too little granularity will affect the reorganization of knowledge objects, so the size of the knowledge granularity of the principle is: "In the maintenance of the local integrity of curriculum knowledge, the knowledge to the corresponding teaching steps" . [8]

Through the teaching of the first-year senior high School "Information Technology Foundation" textbook, relevant lesson plans, courseware research, fully collect curriculum knowledge information, understand the organization structure of curriculum knowledge, according to uniqueness, the same level of disjoint principle, carrying on the extraction of curriculum concept, curriculum knowledge object formation Four layers of granularity division: Top Layer root node (Information Technology Foundation) Six core concepts (characteristics of information, information technology, access to information, information processing, information management, information Security), the first level of the concept of 25 (value, timeliness ... network use norms, network ethics), two-level sub concept over 100, the overall coverage of the "Information Technology base" 
curriculum knowledge system, The conceptual hierarchy model of the curriculum Knowledge Ontology of information technology Basics is shown in the following illustration:

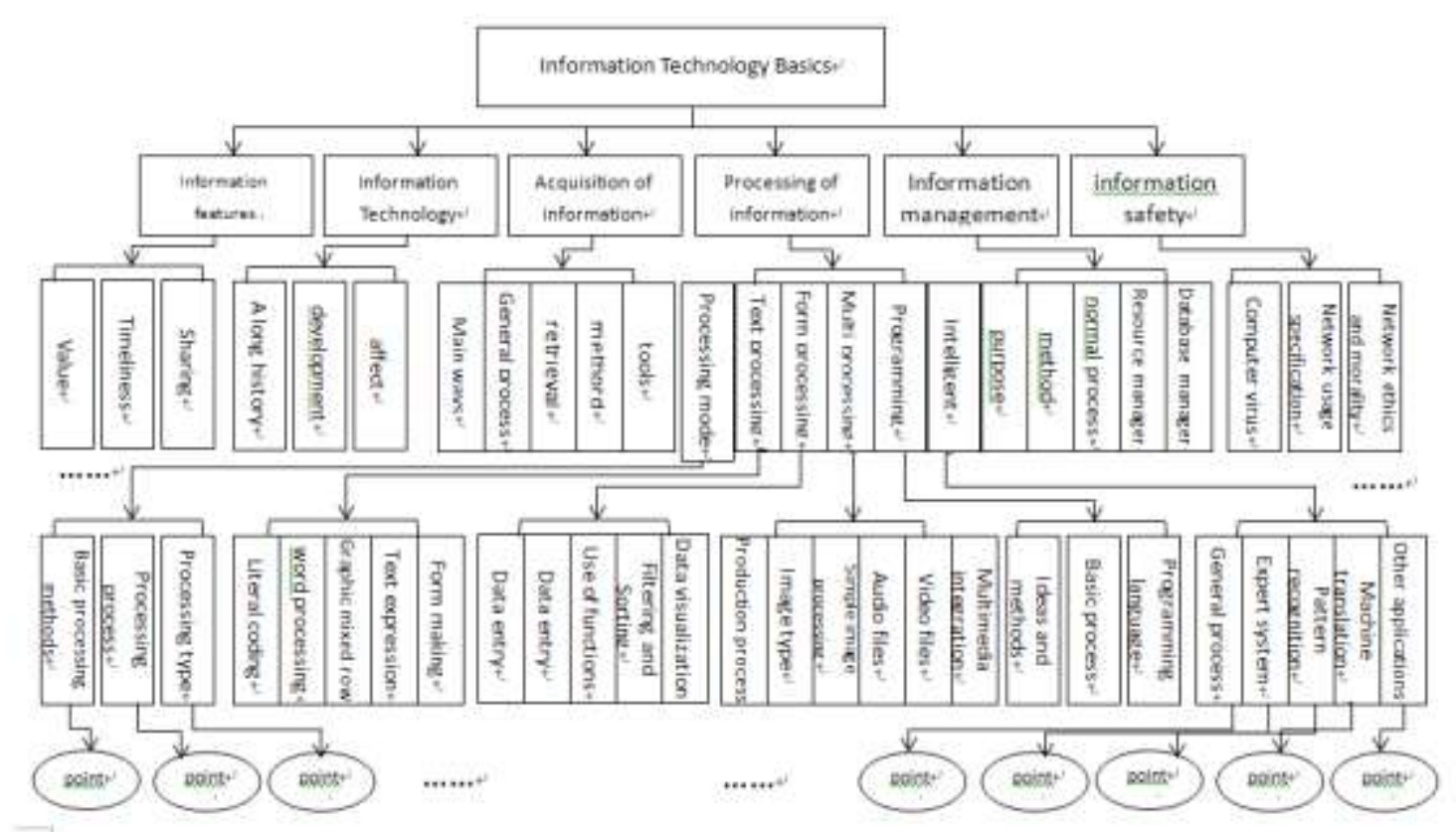

Figure 2. Finite The conceptual hierarchy model of knowledge ontology in Information Technology Foundation Course

Determine the Object Attribute and Relation of Knowledge Ontology in the Course of Information Technology Foundation. After the concept hierarchy of Curriculum knowledge ontology is determined, the curriculum Knowledge ontology Framework is set up, then the concept attribute and semantic relation need to be determined to enrich the concrete content of curriculum knowledge ontology. The concept attribute determines the nature and characteristics of the concept, the definition of concept attribute is realized, and the inheritance of object attribute should be paid attention to to avoid the redundancy of information. The attributes of the concept of knowledge ontology in the course of information technology basics are:

- The concept of the name: the realization of the concept of the distinction between.

- Teaching Objectives: to express the concept of curriculum knowledge and knowledge points to achieve the teaching purposes.

- Keywords: used in the curriculum knowledge of concepts and knowledge points of the search.

- Size: Indicates the content of relevant knowledge points.

- Types: The specific types of knowledge points, such as: Concepts, theorems, experiments, physical phenomena and so on.

- Importance: Describe the importance of knowledge points in the curriculum knowledge structure, such as: Understanding, memory, mastery, understanding and so on.

Difficulty: Describe the knowledge points in the learning process difficult degree, such as: difficult, Medium, general, easy and so on. After the object attribute of the course knowledge ontology of Information Technology Foundation is determined, then we should determine the relevance of the object, the determination of the relationship between the objects, to embody the course of teaching law and teaching materials, to organize the isolated knowledge points in the course, which is beneficial to the reorganization of learners ' knowledge and the implementation of individualized autonomous learning activities.

There are three kinds of relationship among knowledge ontology knowledge points in Information technology basics: Precursor relationship, successor relationship and related relationship: 
- Pre-relationship: used to represent the basic knowledge that should be available before learning this knowledge point. Such as: "Graphic mixed row" This knowledge point before studying, should first learn "word processing", "image insertion" These knowledge points, they are "graphic mixed row" precursor knowledge points.

- Successor: Used to indicate that after learning the current knowledge point can learn those knowledge points, the precursor relationship and the successor relationship is mutually inverse. For example: "Filter and Sort" is the successor knowledge point of "function usage".

- Related relations: Used to express the same level of knowledge points under the compound knowledge point, they have no precursor, successor relationship, in the same hierarchy.

Constructing the Knowledge Ontology of the Course of Information Technology Foundation. The construction software of the Knowledge ontology of the course of information technology has protégé4.1+ graphviz-2.4, protégé4.1 +graphviz-2.4, which are popular ontology editing software combination. All these software use the graphical operation interface, and support the Chinese display of the class structure diagram, which can improve the efficiency of the ontology construction and maintenance work. The construction of Knowledge ontology in the course of Information Technology Foundation adopts the "seven Steps" proposed by Stanford University Medical School, and follows the "norms of educational resources construction (CELTS-41)" and the course teaching rules and teaching procedures. Curriculum Knowledge ontology identified five chapters ontology, 25 units, 105 knowledge points, set up a number of object relationships and data relationships. It involves all the core concepts and knowledge points in the course, describes the semantic relationship between curriculum knowledge, and shows the knowledge system of Information Technology Foundation, which is logically rigorous, has good integrity, and has strong expansibility, which is individualized learning, intelligent answering, Semantic retrieval and other software development lay the foundation.

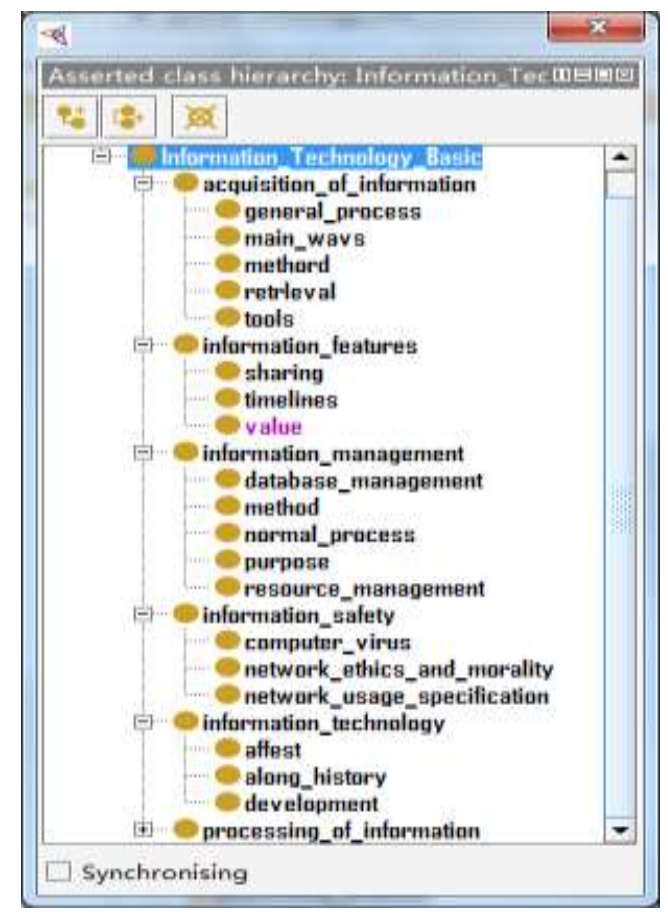

Figure 3. Finite Course ontology class diagram 


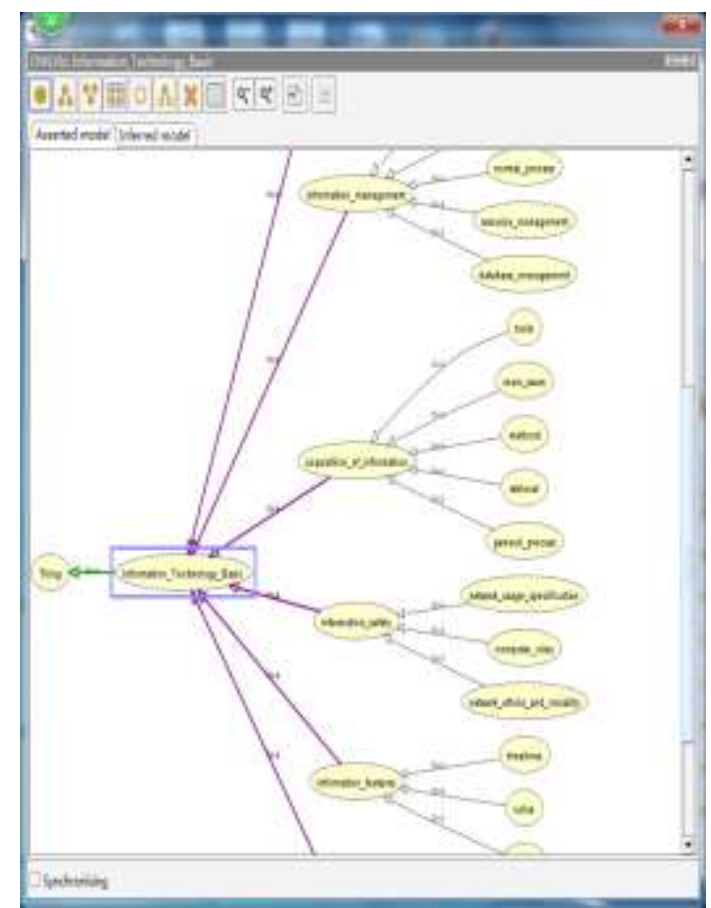

Figure 4. Finite Local structure map of curriculum Ontology

\section{Summary}

Semantic Web is the development direction of web technology nowadays; ontology is an important part of Semantic Web. The ontology of curriculum knowledge is a clear and standardized description of the relationship between concepts in a certain course, and the knowledge system which is built on the basis of common recognition. At present, there are many problems in the course of construction and use of web-based learning resources, such as repetitive construction, resource sharing difficulties and Information Island. Secondly, the curriculum network learning resources in the construction process did not follow the unified technical standards; it is difficult to realize the use of network resources and interoperability. This paper takes the first grade "Information Technology Foundation" curriculum Knowledge ontology construction as an example, firstly, this paper introduces the unified standard for the construction of network Learning Resources: "Technical specification of educational resources Construction in China" (CELTS); Then, in order to solve the problem of the logical relationship of the hierarchical structure of network resources in the course of information technology in middle school, it introduces the ontology, According to the teaching order of course knowledge, follow the teaching law of the course, select the key concepts in the course, define the relationship between concepts, and combine the ontology construction method which is widely used to realize the knowledge ontology of Information Technology Foundation, and realize the individualized learning, intelligent answer and the research of semantic retrieval lays the foundation.

\section{References}

[1] [J]. Liang, Zhou Haiyan. Ontology and Semantic Web Journal of Beijing Union University, 2007, (3), 1-6

[2] [OL].China ELearning Technology Standardization $\quad$ Committee https://baike.baidu.com/item/CELTSC/10811351?fr=aladdin

[3] [OL].What is the meaning of "metadata"?

https://blog.csdn.net/wwww_dong/article/details/53694748

[4] [J]. Liu Baisong. Knowledge based Semantic Web: concepts, techniques and challenges

Journal of Chinese Library, 2003, (2), 1-4 
[5] [J]. GRUBER,T.R.A translation approach to portable Ontology specification Knowledge acquisition, 1993 (5): 199-220

[6] [J]. Teng, Dong, Ming Zhang, et ontology Research review.Journal of Peking University, 2002, (5), $730-738$

[7] [J]. Xiaoyong DU, study on the construction method of knowledge ontology in Ma Wenfeng discipline domain.Library and information Work, 2005, (8), 74-78

[8] [D]. Xiaodong WANG, Research on modeling and application of ontology Knowledge Base system. Shanghai: East China Normal University, 2003 